\title{
FRACTIONAL COMPOSITION AND RHEOLOGICAL PROPERTIES OF PPA MODIFIED NATURAL BITUMEN
}

\author{
Arogundade Obafemi \\ Department of Chemistry
}

Federal University of Technology,

Akure, Ondo State, Nigeria

\author{
Aderinola Olumuyiwa \\ Department of Civil Engineering \\ Federal University of Technology, \\ Akure, Ondo State, Nigeria.
}

\author{
Ogunsuyi Olayinka \\ Department of Chemistry \\ Federal University of Technology, \\ Akure, Ondo State, Nigeria
}

\author{
Aiyesanmi Ademola \\ Department of Chemistry \\ Federal University of Technology \\ Akure, Ondo State, Nigeria \\ Oloye Mariam \\ Department of Chemistry \\ Federal University of Technology \\ Akure, Ondo State, Nigeria.
}

\begin{abstract}
The characteristic properties of Bitumen related to its consistency, namely, softening point and penetration value at $25^{\circ} \mathrm{C}$ form the basis for its grading system. These properties can be altered, in line with the required performance properties, in the refining process or via modification with additives. This work reports the use of polyphosphoric acid (PPA) for the modification (at $160^{\circ} \mathrm{C}$ and $240^{\circ} \mathrm{C}$ ) of the Agbabu natural bitumen in south west Nigeria. The unmodified natural bitumen and PPAmodified bitumen were characterized by standard methods (penetration, softening point, dynamic viscosity and penetration index) and SARA analysis. The results showed higher asphaltenes and lower resin contents in PPA-modified bitumen while the saturates, remained unchanged after modification at both temperatures. The consistency test, revealed a reduction in penetration point, increase in softening point and an increase in the dynamic viscosity with an increase in the PPA dosage at the two temperatures of modification. These findings showed an improved consistency and temperature susceptibility of the modified bitumen.
\end{abstract}

Keywords - bitumen; pavement; rheology; SARA.

\section{INTRODUCTION}

Bitumen serves as a binder in asphalt concrete, a composite material used in the construction of road layers which contain mineral aggregate, filler and additives. Despite its low content (ca. 5\%) the effect of bitumen on properties of concrete and, therefore, on the pavement performance is critical. Bitumen for paving construction is expected to possess a wide range of viscoelasticity, in order to achieve long-lasting road surface and consistency of rheological state in extreme service temperatures (Loeber et al., 1998). However, the chemistry of bitumen shows that it is a complex chemical mixture of hydrocarbon molecules with minor amounts of structurally analogus heterocyclic species and functional groups containing sulphur, nitrogen and oxygen atoms and trace quantities of metals (Ogunsuyi et al., 2011). The chemical complexity of bitumen necessitates the approach of analyzing it based on families of compounds: Saturates, Aromatic, Resins, and Asphaltenes, often called SARA fractions (Shahriar et al, 2017). These SARA fractions play a vital role in the mechanical and rheological properties of bitumen (Jaroszek, 2012); The saturates fraction contains linear and branched alkanes eluted with a paraffinic solvent (e.g., n-hexane), the aromatics fraction is constituted mainly by alkylated $\mathrm{C}_{5}$ and $\mathrm{C}_{6}$ cyclic structures eluted with a moderately polar solvent (e.g., toluene), the resins are alkylated and cycloalkylated structures with 2-3 aromatic rings (e.g., eluted with tetrahydrofuran), and asphaltenes are heavier aromatic polycyclic structures (Catarina et al., 2016); the aromatics and saturates serve as the continuous phase while the aphaltenes remain as the dispersed phase stabilized by the resins in the continuous matrix (Leuseur, 2009). According to the colloidal model, the asphaltenes are somewhat spherical, cylindrical, or flat sheet objects stabilized by a peripheral resins layer. Asphaltenes aggregate and resins remain dispersed in the continuous medium of aromatics and resins. In order to improve bitumen's viscoelasticity, modifiers are applied to neat bitumen. Examples of such modifiers are; elastomers, plastomers, synthetic resins, crumb rubber, metalorganic compounds, sulfur, natural asphalts, paraffins and acids (Golzin and Hamid, 2011). However, the major acid currently in use for refinery-sourced bitumen modification is Polyphosphoric Acid (PPA) (Shahriar, 2017). Several authors (Baldino, 2013; Lesueur, 2009; Masson, 2008; Masson and Collins, 2009; Rossi et al., 2012) have studied the interaction of PPA with bitumen model compounds. From these studies, it 


\section{International Journal of Engineering Applied Sciences and Technology, 2020 \\ Vol. 5, Issue 7, ISSN No. 2455-2143, Pages 1-6 \\ Published Online November 2020 in IJEAST (http://www.ijeast.com)}

became clear that PPA modification follows different mechanisms depending on the chemical composition of bitumen which is strongly related to the crude oil geographical source. Generally, the reactivity of PPA increases with the polarity of the bitumen enclave because polarity enhances PPA dissociation (into $\mathrm{PPA}^{-}$and $\mathrm{H}^{+}$) disrupting the hydrogen bond network formed within the agglomerates of asphaltene micelles (Catarina et al., 2016). Consequently, the molecular weight of the asphaltene fraction is lowered and the distribution of asphaltenes in the remaining fractions (i.e., saturates, aromatics, and resins, usually called maltene phase) is improved, shifting the bitumen towards a more elastic geltype structure, as represented schematically in Figure 1 (Golzin and Hamid, 2011). Although the greater proportion of bitumen used for highway construction worldwide is from crude oil distillation in the refinery, increasing attention is being paid to natural bitumen deposits because they tend to adhere better to the surface of mineral aggregates in asphaltic concrete due to their composition and in particular higher content of oxygen and asphaltogenic acids (Adedimula, 2000). However, not all naturally occurring bitumen meet the requirements for use in road construction leading to the need for modification (Petersen, 1987). This research was therefore aimed at examining changes in the chemical composition and rheological state of the natural bitumen in Agbabu, Nigeria when modified with PPA. The SARA fractions were considered to quantify the compositional changes and effects of these fractions on some of the rheological properties of the tested asphalt binders were discussed.

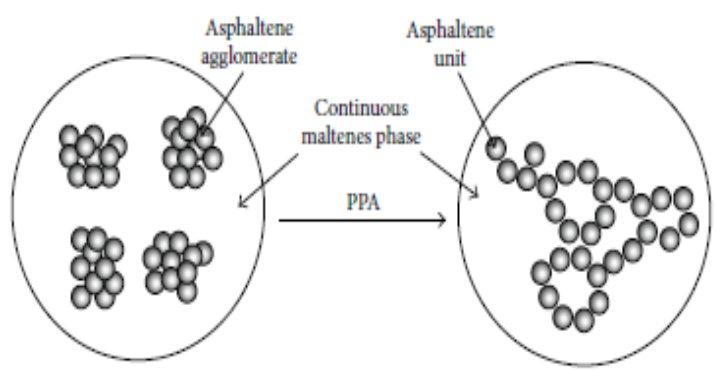

Fig.1: Effect of PPA on Bitumen (Golzin and Hamid, 2011)

\section{MATERIALS AND METHODOLOGIES.}

The natural bitumen was collected from one of the wells sunk by the Nigerian Bitumen Corporation (NBC -7) located opposite Saint Stephen's Primary School, Agbabu, Ondo State, Nigeria. Agbabu is located on the bitumen belt of southwestern Nigeria. The belt lies within latitude $0060381 \mathrm{~N}$ $0060401 \mathrm{~N}$ and longitude 0040341E-0040371E, falls within the eastern Dahomey Basin and spans across Edo, Ondo and Ogun States (Bakare, et al., 2016).

\section{Modifier}

The modifier used in this study was polyphosphoric acid (PPA) with concentration of $105 \%$ phosphoric acid (84\% $\mathrm{P}_{2} \mathrm{O}_{5}$ ). The specific gravity is $2.06 \mathrm{~g} / \mathrm{ml}$.

\section{Purification of natural bitumen}

The natural bitumen sample collected from Agbabu was dehydrated and then purified as described by (Bakare et al., 2015): $100 \mathrm{~g}$ of the sample was spread on a tray to a thickness of $1 \mathrm{~cm}$. Then, $1.0 \mathrm{~g}$ of calcium chloride was spread over the sample at room temperature and the mixture stirred manually with stirring rod for $5 \mathrm{~min}$. This mixture was taken to an oven regulated at $65^{\circ} \mathrm{C}$ to remove adhering moisture. The dehydrated bitumen was dissolved in $1000 \mathrm{~mL}$ of chloroform and filtered. The bitumen portion of the filtrate was recovered by vacuum evaporation of the solvent.

\section{Preparation of PPA modified Bitumen.}

The PPA modified samples were prepared using a shear mixer. (100g) of the natural bitumen (UNB) was heated to fluid state in an iron container. When the temperature of UNB was $160^{\circ} \mathrm{C}$, the PPA was gradually added. The temperature of the mixture was maintained at $160^{\circ} \mathrm{C}$ with the speed of the mixer also maintained at $1200 \mathrm{rpm}$ for $1 \mathrm{hr}$ to obtain a homogenous mixture. The three modified binder formulations prepared at $160{ }^{\circ} \mathrm{C}$ with $2 \%, 4 \%, 6 \%$ of PPA are termed PPAMB2160, PPAMB4160, PPAMB6160 while the other set prepared at $240{ }^{\circ} \mathrm{C}$ with $2 \%, 4 \%, 6 \%$ of PPA is termed PPAMB2240, PPAMB4240, PPAMB6240 respectively.

\section{SARA fraction:}

$100 \mathrm{~g}$ of the bitumen was heated in a 1-litre thermostatic heating mantle assembled with a flat bottom Pyrex flask containing $200 \mathrm{~mL}$ of $\mathrm{n}$-pentane and refluxed for $2 \mathrm{~h}$ at a temperature regulated at $45^{\circ} \mathrm{C}$. This led to two phases(raffinate and extract), which were carefully separated and weighed after evaporating the solvent. The raffinate was the Asphaltene. To obtain the saturates, aromatics and resin, the extract was poured into a column, $60 \mathrm{~cm}$ long and $1.6 \mathrm{~cm}$ wide, halfway packed with $80 \mathrm{~g}$ of alumina gel (fully activated Brockman Activity 11) and top half with $62 \mathrm{~g}$ of silica gel (fully activated 250-125 mm). Saturates will be eluted with $1: 1(\mathrm{v} / \mathrm{v})$ hexane - cyclohexane mixture, aromatics eluted with 7:3 (v/v) hexane - toluene mixture while resins will be eluted with $7: 3(\mathrm{v} / \mathrm{v})$ tetrachloromethane - chloromethane mixture. Rheological properties of modified and unmodified UNB

The following rheological properties of the PPA modified ANB were determined using appropriate standard procedures. They are: Softening point (ASTM-D36), Penetration point (ASTM-D5-97), Dynamic viscosity (ASTM-D2171-92).

\section{Penetration index of PPA modified and unmodified bitumen.}

The susceptibility of bitumen samples to the effect of temperature changes was calculated in terms of penetration 


\section{International Journal of Engineering Applied Sciences and Technology, 2020 \\ Vol. 5, Issue 7, ISSN No. 2455-2143, Pages 1-6 \\ Published Online November 2020 in IJEAST (http://www.ijeast.com)}

index (PI) using the results obtained from penetration and softening point tests. The PI was calculated using the equation (Roque, 2004) as shown below:

$$
P I=\frac{1952-500 \log (\text { pen } 25)-20 \times S P}{50 \log (\text { Pen } 25)-S P-120}
$$

Where $\mathbf{P}_{25}$ is the penetration at $25^{\circ} \mathrm{C}$ and SP is the softening point temperature of the modified bitumen samples.

\section{RESULTS AND DISCUSSION}

\section{Effect of PPA on SARA fractions of the natural bitumen.}

The SARA fractions of the natural bitumen before and after PPA modification are presented in Tables $\mathbf{1}$ and 2 . Modification with PPA did not lead to a significant change in the saturates at both temperatures. This was not unexpected, because the saturates are non-polar and reactivity of the polyphosphoric acid depends largely on the polarity of the enclaves in which it is found (Jarosjek, 2012).

Table 1: SARA fractions of the unmodified natural bitumen, UNB.

\begin{tabular}{lc}
\hline Binder & $\mathrm{UNB}$ \\
\hline Saturates. & $10.08^{\mathrm{a}} \pm 0.06$ \\
Aromatics. & $36.00^{\mathrm{a}}+0.05$ \\
Resins & $30.47^{\mathrm{ag}} \pm 0.07$ \\
Asphaltenes & $23.45^{\mathrm{a}} \pm 0.04$ \\
\hline
\end{tabular}

However, after modification, there was a significant drop in the aromatics and resins at the two temperatures. Aromatics dropped from $(36.00 \pm 0.05)$ in the natural bitumen to a range of $(31.94 \pm 0.43$ to $33.31 \pm 0.31)$ in the PPA modified binder, while resins reduced significantly from $30.47 \pm 0.07$ in the natural bitumen to a range of $(27.44 \pm 1.21$ to $30.10 \pm 0.03)$ in the PPA modified binder. This result is consistent with the report by (Shahriar et al., 2017) who carried out changes in fractional compositions of PPA and SBS modified asphalt binders. The asphaltenes fractions in the modified binders however increased significantly. This is because the effect of PPA on bitumen modification has been associated with redox reactions involving polycondensed aromatic structures that act as reducing agents for phosphoric acid oligomers $\left(\mathrm{H}_{3} \mathrm{PO}_{4}\right)$ which are therefore oxidized. As a result, there would be conversion of part of the resins fraction into asphaltenes (Catarina et al., 2016). It is also noteworthy that the SARA fractions for the modified binders at $160^{\circ} \mathrm{C}$ and $240^{\circ} \mathrm{C}$ are similar; as such, as shown in Fig.3 and Fig.4, the percentage dosage of the PPA had the same effect on the SARA fractions regardless of the temperature of modification.

Table 2: SARA fractions of the PPA-modified natural bitumen, PPAMB.

PPAVB2160 PPAVIB4160 PPAVIB6160 PPAVIB2240 PPAIIB4240 PPAMB6240

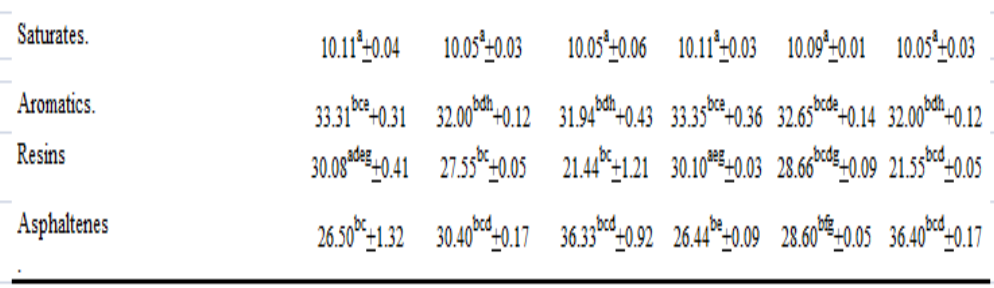

Figs.3 and 4 display the variations in SARA fractions with ascending percentages of PPA at ${ }^{\circ} 0^{\circ} \mathrm{C}$ and $240^{\circ} \mathrm{C}$. The percentages of saturates remained almost constant regardless of the temperature. However, aromatics and resins were continuously decreasing with PPA addition since it was turning into Asphaltenes.

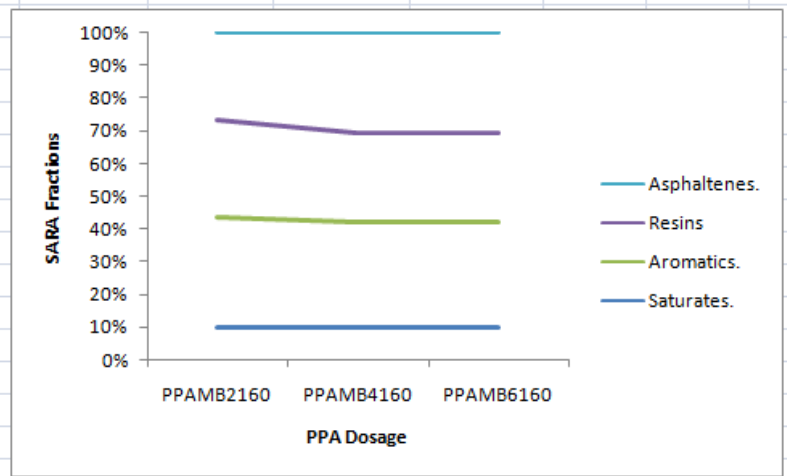

Fig.3: Changes in SARA content with PPA modification at $240^{\circ} \mathrm{C}$

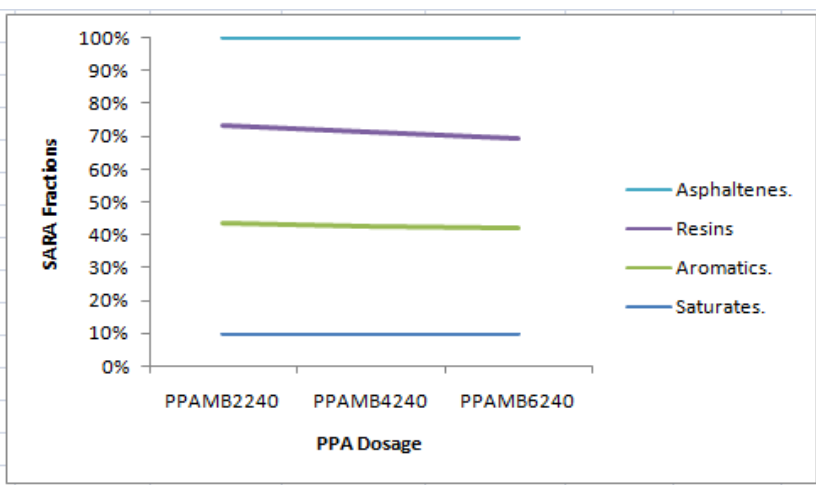

Fig.4: Changes in SARA content with PPA modification at $240^{\circ} \mathrm{C}$ 


\section{International Journal of Engineering Applied Sciences and Technology, 2020 \\ Vol. 5, Issue 7, ISSN No. 2455-2143, Pages 1-6 \\ Published Online November 2020 in IJEAST (http://www.ijeast.com)}

\section{Rheological properties of unmodified and modified ANB}

The penetration point is a consistency test that is used to designate the grade of bitumen. The higher the penetration point, the softer the bitumen material. Increase in penetration point indicates increase in hardness of modified bitumen (Gaylon et al., 2008). For highway pavement in a tropical region such as Nigeria, bitumen used as binders in such pavements are often graded Pen 60/70. This grade means the penetration point is to fall within 60 and 70. Shiva and Prasad. (2012) reported that bitumen grade $60 / 70$ at $25^{\circ} \mathrm{C}$ had a penetration of 67; and grade 80/100 had penetration of 90 .

Table 3: Rheological properties of the unmodified natural bitumen, UNB.

\begin{tabular}{cc}
\hline Binder & UNB \\
\hline Penetration Point (dmm) & 92 \\
Softening Point (oC) & 35.4 \\
Viscosity (Pas) & 81 \\
Penetration Index & -0.24 \\
Predictive Grade & Pen $80 / 100$ \\
\hline
\end{tabular}

Table 4:

\begin{tabular}{cccc}
\hline Binder & PPAMB2160 & PPAMB4160 & PPAMB6160 \\
\hline Penetration Point (dmm) & 82 & 68 & 55 \\
Softening Point (0C) & 42.5 & 55.9 & 58.5 \\
Viscosity (Pas) & 105 & 155 & 164 \\
Penetration Index & -1.27 & 0.64 & 0.68 \\
Predictive Grade & Pen 80/100 & Pen 60/70 & Pen 40/50 \\
\hline
\end{tabular}

Table 5:

\begin{tabular}{lcccc}
\hline Binder & UNB & PPAMB2240 & PPAMB4240 & PPAMB6240 \\
Penetration Point & 92 & 82 & 67 & 53 \\
Softening Point $\left({ }^{\circ} \mathrm{C}\right)$ & 35.4 & 41.9 & 55.3 & 57.2 \\
Viscosity (Pas) & 81 & 105 & 150 & 156 \\
Penetration Index & -0.24 & -1.38 & 0.53 & 0.42 \\
Predictive Grade & Pen $80 / 100$ & Pen $80 / 100$ & Pen $60 / 70$ & Pen $40 / 50$ \\
\hline
\end{tabular}

Table 3 indicates that the unmodified Agbabu natural bitumen had a penetration point of $92 \mathbf{d m m}$ which made it fall outside the range for paving grade bitumen on the highways in Nigeria. The result which is very similar with the ones observed by (Bakare, et al., 2016) implies that the natural bitumen would be too soft for the purpose of paving on the highways. However, modification of the bitumen with PPA resulted in a decrease in the penetration point, indicating some level of hardness: Penetration point values ranged from 58 $\mathrm{dmm}$ to $82 \mathrm{dmm}$ at $160^{\circ} \mathrm{C}$ and $53 \mathrm{dmm}$ to $82 \mathrm{dmm}$ at $240^{\circ} \mathrm{C}$. This result compares favourably with the one reported by Bakare, et al., 2016 who modified the Nigerian bitumen with PPA at $160^{\circ} \mathrm{C}$. Even though work on modification of the natural bitumen at a much higher temperature, such as $240^{\circ} \mathrm{C}$ had not been reported in literature, this result indicates that there was no significant effect of temperature on the penetration point of the PPA modified bitumen at $240^{\circ} \mathrm{C}$. The amount of PPA however had a more significant effect on the result obtained: Table 4 and Table 5 show that the highest penetration value was 82 when $2 \%$ PPA was added, this further reduced as PPA content was increased. A similar trend was observed for PPA modified binder at a temperature of $240^{\circ} \mathrm{C}$ with the highest penetration of 82 at $2 \%$ PPA modification, and the lowest at $6 \%$ PPA. Considering the standard for consistency test, penetration point beyond the minimum (60) and maximum (70) is not recommended for paving grade bitumen of Pen 60/70, hence only $4 \%$ PPA modification at $160^{\circ} \mathrm{c}$ and $4 \%$ PPA modification at $240^{\circ} \mathrm{c}$ gave penetration points within the recommendation values. PPAMB6160 and PPAMB6240, graded as Pen 40/50, had the highest asphaltene fractions, and lowest resin fractions. A bitumen colloidal solution with low resin and high asphaltene fraction has gel properties. On the other hand, PPAMB4160 and PPAMB4240, graded as Pen 60/70 had higher resin fractions compared to that Pen 40/50, this meant a higher capability to peptize the asphaltenes, thereby reducing the hardness. For PPAMB2160 and PPAMB4160, the low asphaltenes, high resin, and high aromatic fraction; this greatly softens the bitumen, thus increasing the penetration point (Leseuer, 2009). Asphaltenes seemed to serve as a viscosity building component (Shahriar et al, 2017); this can be seen in the results of the Dynamic Viscosity, as shown in Tabe 4, the higher the asphaltenes, the higher the dynamic viscosity of the modified binder. The Dynamic viscosities of PPA modified samples which ranged from 105 Pas for 2\% PPA modified sample to 156 Pas for $6 \%$ PPA modified sample were found to be relatively higher than that of unmodified natural bitumen, (UNB) (81Pas).

The softening point of PPA modified samples increased from $41.9^{\circ} \mathrm{C}$ for $2 \%$ PPAMB at $160{ }^{\circ} \mathrm{C}$ to $58.5^{\circ} \mathrm{C}$ for $6 \%$ PPAMB at $160{ }^{\circ} \mathrm{C}$ as against that of UNB which was $35.4{ }^{\circ} \mathrm{C}$. The penetration indices of PPA modified ANB samples increased as the percentage content of PPA incorporated increased (Table 2). This is an indication of an increased resistance of PPA modified samples to temperature susceptibility after modification. 


\section{International Journal of Engineering Applied Sciences and Technology, 2020 \\ Vol. 5, Issue 7, ISSN No. 2455-2143, Pages 1-6 \\ Published Online November 2020 in IJEAST (http://www.ijeast.com)}

Table 4: Rheological properties of PPA-modified bitumen.

Bitumen: Standard Characterization and NMR Insights, Journal of Analytical Methods in Chemistry PPol

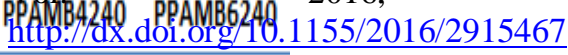

pp.16-22.

\begin{tabular}{|c|c|c|c|c|c|}
\hline Binder & PPAMB2160 & PPAMB4160 & PPAMB6160 & PPAMB2240 & 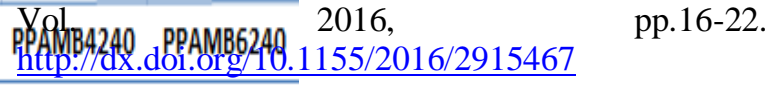 \\
\hline Penetration Point (dmm) & 82 & 68 & 55 & 828 & $\begin{array}{l}\text { Gayfon, B. L.53 Masson, J., Hardee, J. R., Menapace, } \\
\text { A. M., and Williams, A. G. (n.d.). Polyphosphoric }\end{array}$ \\
\hline Softening Point $(0 \mathrm{C})$ & 42.5 & 55.9 & 58.5 & 41.9 & $\begin{array}{l}\text { Aciøl3Modifieg.2Asphalt: Proposed Mechanisms: Part } \\
1 .\end{array}$ \\
\hline Viscosity (Pas) & 105 & 155 & 164 & 1059 & Gol5in, Y. ab 5 Hamid, S. (2011). Improving the \\
\hline Penetration Index & -1.27 & 0.64 & 0.68 & -1.38 & $\begin{array}{l}\text { performance of Crumb Rubber bitumen by means of } \\
\text { PoPy } 3 \text { Phosphofic Acid (PPA) and Vestenamer }\end{array}$ \\
\hline Predictive Grade & Pen $80 / 100$ & Pen 60/70 & Pen 40/50 & Pen 80/100 & $\begin{array}{l}\text { additizes. Construction and Building Materials, } \\
25 \text { (4) } 3108-3196 \text {. }\end{array}$ \\
\hline
\end{tabular}

\section{CONCLUSION}

The Agbabu natural bitumen was analyzed before and after modification with polyphosphoric acid (PPA). SARA analysis revealed that, PPA modification showed higher asphaltenes and lower resin contents while the saturates, remained unchanged after modification at both temperatures. The consistency test, revealed a reduction in penetration point, increase in softening point and an increase in the dynamic viscosity with an increase in the PPA dosage at the two temperatures of modification. These findings showed an improved consistency and temperature susceptibility of the modified bitumen.

\section{REFERENCE}

1 Adedimila, A. S. (2000). Bitumen: Nigeria's other black gold?. Inaugural Lecture Series, University of Lagos.

2 ASTM D2171-92. Standard Test Method for Dynamic Viscosity of Asphalts, Experiment No. 12..

3 ASTM D36/ Standard Test Method for Softening Point of Bitumen (Ring-and-Ball Apparatus). Annual Book of ASTM Standards, Volume 04.03, American Society for Testing and Materials, Philadelphia 19103-1187.

4 ASTM D5-97. (1998). Standard Test Method for Penetration of Bituminous Materials. Annual Book of ASTM Standards, Volume 04.03, American Society for Testing and Materials, Philadelphia 19103-1187.

5 Bakare, H.O., Esan,A.O., and Olabemiwo, O.M. (2015) Characterisation of Agbabu natural bitumen and its fractions using Fourier transform infrared spectrometry, J. Chem. Mater. Res. 7 (8). pp.1-16.

6 Baldino, D., Gabriele, F.R., Lupi, C. Oliviero, R. P., Caputo, T. F., Rheological effects on bitumen of polyphosphoric acid (PPA) addition, Construction Building Materials. 40 (2013) 397-404.

7 Catarina, V., Ribeiro, J., Silva, A. M. S., and Silva, C. M. (2016). Influence of Polyphosphoric Acid on the Consistency and Composition of Formulated
10 Hanna Jaroszek, (2012). Polyphosphoric acid (PPA) in road asphalts modification, CHEMIK 66 Vol. (12) pp. 1340-1345.

11 Lesueur, D. (2009). The colloidal structure of bitumen: Consequences on the rheology and on the mechanisms of bitumen modi fi cation. Advances in Colloid and Interface Science, 145(1-2), 42-82. https://doi.org/10.1016/j.cis.2008.08.011

12 Loeber, L., Muller, G., Morel, J., Sutton, O., Havre, L., and Havre, L. (1998). Bitumen in colloid science: a chemical, structural and rheological approach, E LS EV I E R, 77(13), 1443-1450.

13 Masson, J. F. and Collins, P. (2009). FTIR Study of the Reaction of Polyphosphoric Acid and Model Bitumen Sulfur Compounds, Energy and Fuels, vol. 23, 440-442.

14 Masson,J.F. (2008). "Brief review of the chemistry of polyphosphoric acid (PPA) and bitumen," Energy and Fuels, vol.22, no.4,pp. 2637-2640.

15 Ogunsuyi, H.O., Ajayi O.O., and Abayomi T.G. (2011). Chemical analysis of Agbabu Exudate as potential refinery feedstock. Journal of Applied Science and Technology, vol.16,1-2.

16 Olabemiwo, O. M., Esan, A. O., Adediran, G. O., \& Bakare, H. O. (2016). Case Studies in Construction Materials The performance of Agbabu natural bitumen modified with polyphosphoric acid through fundamental and Fourier transform infrared spectroscopic investigations. Case Studies in Construction Materials, 5, 39-45. https://doi.org/10.1016/j.cscm.2016.06.003

17 Peterson, J. (1987). Potential use of tar sand for paving applications.

18 Roque, R B., Birgisson, M., Tia, B. K., and Cui, Z. (2004). Guidelines for the Use of Modifiers in Superpave Mixture: Evaluation of SBS Modifier, State Job 99052793, Florida Department of Transport, Tallaassee, FL.

19 Rossi, L., Seta, N., Baldino, D. Gabriele,C.O., F. R. Lupi,and P. Caputo, (2012). "Low temperature rheology of polyphosphoric acid (PPA) added 
International Journal of Engineering Applied Sciences and Technology, 2020

Vol. 5, Issue 7, ISSN No. 2455-2143, Pages 1-6

Published Online November 2020 in IJEAST (http://www.ijeast.com)

bitumen," Construction and Building Materials, vol. 36, pp. 592-596.

20 Shiva P.K., Manjunath K.R. and Prasad K.V.R. (2012). Study on Marshall Stability Properties of BC Mix Used in Road Construction by Adding Waste Plastic Bottles. IOSR Journal of Mechanical and Civil Engineering. Vol 2, Issue 2 PP 12-23 